\title{
ECONOMICS
}

\section{INTEGRATED SUPPORT SYSTEM OF PROCESS MANAGEMENT OF INNOVATIVE PROJECTS}

\author{
Maria Abuzjarova ${ }^{1}$
}

\begin{abstract}
The relevance of the article is due to the current economic situation in the development of innovative products and services, which remains a strategic priority for most companies, regions, states, and many of them consider innovation as a serious growth factor. In order to develop new methods for assessing the effectiveness of the innovation portfolio, the urgent task is to promote the growth and diversification of the economy, attracting investments, improving clusters, improvement and strategic development of the country's science and technology, which involves each innovative project moving to a new level of expertise. The implementation of innovative projects is characterized by improving the intellectual resources of the country, as well as the degree of investment in the implementation process. The need to evaluate innovative projects in conditions of state financing is primarily due to the fact that the constructed project cash flows are for future periods and are forecast in nature. This is due to the assessment of the integral indicator of the quality of future competitiveness and the commercialization of a new product / service.
\end{abstract}

Key words: project, innovation project, integration, innovation process.

doi: http://doi.org/10.15350/L_2/5/61

Project management is an effective approach to enterprise management and uses a modern concept to build a management system using automated process control systems.

Project management systems are created according to certain standards and have characteristics that include implementation, deployment, training and support.

The implementation of the system is based on the creation of techniques for managing this system. To clarify the methods, each vendor seeks to advise a potential customer on the importance and features of use.

Depending on the needs, management techniques may be in the form of manuals for use or rules and instructions. Instructions are created for self-implementation. If the system is simple, then the customer engages in the integration process independently and additionally creates his own methodology for various enterprise services for using this system. Terms of use are designed to improve the security of information loss or other actions.

Complex integrated systems require additional training for employees, as well as continuous certification of the use of these systems [1].

${ }_{1}^{1}$ Maria Abuzjarova, Ph.D. in Economics, associate professor, Samara State University of Economics, Russia. 
Thus, employees become narrow specialists, increasing the efficiency of their work using integrated systems. On the other hand, employees become hostages to these systems, because depending on the complexity of the training, employees spend more time working with this system, rather than working in this system.

A harmonious combination in the overall management system is a rather complex parameter, since it includes issues of unity and logic of processes, reduction of duplication of processes and conceptual framework. Vendors at the level of creating their products are trying to maintain unity with popular software tools.

The effectiveness of integration is due to the economic feasibility of integrating automated project management systems.

To date, in the practice of systems integrators, there is no full integration of all enterprise / project management systems into one single one.

As foreign experience shows, this issue is losing its relevance.

In this regard, the enterprise integrates part of the systems, which in their functionality can reduce the level of duplication of actions and increase the efficiency of communications between departments of the enterprise.

The practical issues of integrating project management at the enterprise are approached from the side of introducing automated software and computer systems, or unique independent software into the project management system [2].

When implementing, use two methods:

- using a turnkey solution offered by the IT market;

- development of a unique solution using off-the-shelf platforms.

Both cases in large companies are considered as technological innovation projects aimed at improving processes.

Evaluation of the effectiveness of integration of the EMS depends on the methodology and infrastructure (maturity) of the management information system.

To assess the effectiveness of integration and development of project management systems, we rely on the final economic effect.

It should be noted that an effective and correctly functioning management system and / or its elements should lead the enterprise to certain positive economic results, for example, reducing costs, increasing sales, effectively achieving goals, increasing the wellbeing of the population, creating an image, etc.

To determine the effectiveness of system integration, we will determine the necessary methods for evaluating effectiveness based on their practicality.

You can evaluate performance in the following areas:

- Financial assessment - investment.

- Economic assessment - resource.

- Expert Evaluation - function.

Financial valuation involves investment analysis.

Economic assessment is aimed at ensuring and developing the material and technical (infrastructure) part.

Expert assessment affects the interests of the strategic analysis of the enterprise, taking into account the intended changes.

To assess the effectiveness of the integration of the EMS, it is necessary to form a structure of parameters, which includes cost, costs and other criteria.

The structure of parameters can be differentiated depending on the type of enterprise, project and method of integration.

With vertical integration, costs can be at a low level, unlike horizontal, where it is required to carry out integration processes in all elements of enterprise management.

In practice, the integration process takes a long time. 
Depending on the complexity of the project management system being designed and the implementation of a turnkey solution, there are various degrees of complexity.

The most important cost issues are related to cost-effectiveness.

Fixed and variable costs relate to the process of system integration, as well as subsequent operation.

This includes issues such as the need to create a staff to control and monitor the performance of the system; variable costs include all costs associated with the functioning and development of these systems.

Risks include issues such as intentional hacking and information theft.

Integrated systems contain the entire body of information in one place, and also, based on the processes of system destruction, are deterministic in nature, which, if they fail, lead to financial losses of the enterprise.

The implementation period, in other words, is the integration period.

In practice, the integration process is divided into several stages: consultation, concept development, software development (software), test implementation, troubleshooting, final implementation, methodology development, etc.

In aggregate, this process for large complex solutions can take from six months to three years. Various costs may arise during this period, which affects performance indicators when considering the integration process of a system.

Availability refers to the market performance of management systems. The deeper the market penetration of the system, the more accessible it is for the enterprise.

If this software is in demand, a large number of integrators accordingly appears, which facilitates the integration and further use process.

The difficulty in accessing a software order relates mainly to large vendors and complex systems. As we understand it, these systems are not sold over the Internet or in other lightweight ways. The selling / buying process takes a long time.

To distribute the coefficient of significance, the data of the control system should be separated based on their functional features [3].

Despite the fact that some systems are complex, the main core of the system provides for the presence of one important function, and the rest as additional.

When determining the initial expert assessment, difficulty / lightness levels should be formed for each parameter.

Thus, the rating was set from 1 to 10 depending on the parameter and the system. The estimation of a parameter is derived from each parameter element by the formula of the set of parameter elements multiplied by the significance criterion (1).

$$
A_{r}=\sum_{k=1}^{p} * C_{n}
$$

where $p$-process parameter;

$C$ - significance criterion set based on the functional area of the system.

The final assessment of the system is made from the totality of parameter estimates (2),

$$
E_{x r}=\sum A_{r}(P, F, U)
$$

where $P, F, U$ - set of parameter estimates 
Assessments can be made on the basis of an analysis of the possibilities, advantages and disadvantages, as well as the experience and practice of the functioning of these systems.

In this case, our goal is to evaluate the infrastructure or set of management systems inherent in each enterprise. To do this, we identify the indicator of maturity of business process management using the index of management systems (IMS).

The concept of calculation is somewhat different due to the addition of an additional parameter: enterprise management methodology.

The enterprise management methodology includes the maturity of the management concept, the availability of a strategic plan, the methodology of business processes and other official documentary forms confirming the maturity of the enterprise in the business environment.

The calculation of the index (3) of the control system is performed using the following formula:

$$
I_{m n}=M * \sum_{n=k}^{m} A_{r}(P, F, U)
$$

where:

$I_{m n}$ - control system index;

$M$ - methodology parameter;

$m$ - functional tasks in which the EMS is used.

The methodology of business processes guides the development and integration of project management systems depending on the goals and priorities of the enterprise.

Large national enterprises have quite a lot of experience in enterprise management, in this regard they show good results.

Medium-sized enterprises, which are part of large national companies, differ in average MIS indicators due to the fact that they pay more attention to process management or operational management.

The planned total revenue from the implementation of the project management system integration may include an assessment of effectiveness [4].

For this, it is necessary to calculate the parameter of the business success result (RUB), which indirectly affects the future cash flow.

Next, we include an assessment of the effectiveness of the functioning of control systems and obtain the final parameter of the present value (PV).

The formula will be as follows:

$$
N P V=\sum_{t=1}^{N}\left(\frac{C F_{t} E_{f}}{(1+i)^{t}}\right)-I C
$$

where $E_{f}$-calculated performance index;

Thus, the above assessment confirms the hypothesis that complex software systems are not always effective in the project management system and in managing the enterprise as a whole. In this case, the integration process of simple and independent software systems is an actual solution to increase the efficiency of the enterprise management system and, accordingly, the project management system. 
References

[1] Cuprava T.A. Project management. Introductory course: textbook. - M.: Publishing House of RUDN, 2008. - $121 \mathrm{p}$.

[2] Mazur I.I. and others. Project Management: textbook. / under the general editorship of Mazur I.I. and Shapiro V.D. - 6th ed. - M.: OMEGA-L, 2017. - 960 p.

[3] Sorokina I.O. The theoretical foundations of the concept of integration and the principles of its implementation // Management in Russia and abroad. - 2016. - 2

[4] Zipes G. Project management system: integration approach // Director of IP. - 2013. No. 12 